\title{
Diel timing of nest predation changes across breeding season in a subtropical shorebird
}

\author{
Martin Sládeček ${ }^{1}$, Kateřina Brynychová ${ }^{1}$, Esmat Elhassan ${ }^{1}$, Miroslav Salek $^{1}$, Veronika \\ Janatová $^{1}$, Eva Vozabulová ${ }^{1}$, Petr Chajma ${ }^{1}$, Veronika Firlová ${ }^{1}$, Lucie Pešková ${ }^{1}$, Aisha \\ Almuhery $^{2}$, and Martin Bulla ${ }^{1}$ \\ ${ }^{1}$ Czech University of Life Sciences Prague Faculty of Environmental Sciences \\ ${ }^{2}$ Dubai Municipality
}

May 28, 2021

\begin{abstract}
Predation is the most common cause of nest failure in birds. While nest predation is relatively well studied in general, our knowledge is unevenly distributed across the globe and taxa, with for example limited information on shorebirds breeding in sub-tropics. Importantly, we know fairly little about the timing of predation within a day and season. Here, we followed 444 nests of red-wattled lapwings (Vanellus indicus), a ground-nesting shorebird, for a sum of 7828 days to estimate a nest predation rate, and continuously monitored 230 of these nests for a sum of 2779 days to reveal how the timing of predation changes over the day and season in a sub-tropical desert. We found that 312 nests $(70 \%)$ hatched, 76 nests $(17 \%)$ were predated, $23(5 \%)$ failed for other reasons and $33(7 \%)$ had an unknown fate. Daily predation rate was $0.95 \%$ (95\%CrI: $0.76 \%-1.19 \%)$, which for a 30-day long incubation period translates into $\sim 25 \%(20 \%-30 \%)$ chance of nest being predated. Such a predation rate is low compared to most other avian species. Predation events $(\mathrm{N}=25)$ were distributed evenly across day and night, with a tendency for increased predation around sunrise. Predation rate and events were distributed evenly also across the season, although night predation was more common later in the season, perhaps because predators reduce their activity during daylight to avoid extreme heat. Indeed, nests were never predated when mid-day ground temperatures exceeded $45^{\circ} \mathrm{C}$. Whether the diel activity pattern of resident predators undeniably changes across the breeding season and whether the described predation patterns hold for other populations, species and geographical regions awaits future investigations.
\end{abstract}

\section{Hosted file}

Sladecek_et_al_2020_revision_final.pdf available at https://authorea.com/users/387677/ articles/523904-diel-timing-of-nest-predation-changes-across-breeding-season-in-asubtropical-shorebird 